\title{
Endoscopic Endonasal Transplanum Transtuberculum Approach for the Resection of a Large Suprasellar Craniopharyngioma
}

\author{
João Mangussi-Gomes ${ }^{1}$ Eduardo A. Vellutini ${ }^{2}$ Huy Q. Truong ${ }^{3}$ Felix H. Pahl ${ }^{2}$ Aldo C. Stamm ${ }^{1}$
}

${ }^{1}$ ENT Center (COF) - Professor Edmundo Vasconcelos Hospital,

Address for correspondence João Mangussi-Gomes, MD, ENT Center São Paulo, São Paulo, Brazil (COF), Professor Edmundo Vasconcelos Hospital, 1450 Borges Lagoa

${ }^{2}$ DFVNeuro - Neurology \& Neurosurgery Group, São Paulo, St., São Paulo-SP, Brazil (e-mail: joaopauloemt@gmail.com).

São Paulo, Brazil

3 Surgical Neuroanatomy Laboratory, University of Pittsburgh School of Medicine, Pittsburgh, Pennsylvania, United States

J Neurol Surg B 2018;79(suppl S3):S249-S250.

\begin{abstract}
Keywords

- transnasal endoscopic surgery

- transnasal endoscopic microsurgery

- suprasellar cyst

- craniopharyngioma

Objectives To demonstrate an endoscopic endonasal transplanum transtuberculum approach for the resection of a large suprasellar craniopharyngioma.

Design Single-case-based operative video.

Setting Tertiary center with dedicated skull base team.

Participants A 72-year-old male patient diagnosed with a suprasellar craniopharyngioma. Main Outcomes Measured Surgical resection of the tumor and preservation of the normal surrounding neurovascular structures.

Results A 72-year-old male patient presented with a 1-year history of progressive bitemporal visual loss. He also referred symptoms suggestive of hypogonadism. Neurological examination was unremarkable and endocrine workup demonstrated mildly elevated prolactin levels. Magnetic resonance images demonstrated a large solid-cystic suprasellar lesion, consistent with the diagnosis of craniopharyngioma. The lesion was retrochiasmatic, compressed the optic chiasm, and extended into the interpeduncular cistern (-Fig. 1). Because of that, the patient underwent an endoscopic endonasal transplanum transtuberculum approach. ${ }^{1-3}$ The nasal stage consisted of a transnasal transseptal approach, with complete preservation of the patient's left nasal cavity. ${ }^{4}$ The cystic component of the tumor was decompressed and its solid part was resected. It was possible to preserve the surrounding normal neurovascular structures (-Fig. 2). Skull base reconstruction was performed with a dural substitute, a fascia lata graft, and a right nasoseptal flap (-Video $\mathbf{1}$ ). The patient did well after surgery and referred complete visual improvement. However, he also presented panhypopituitarism on long-term follow-up.
\end{abstract}

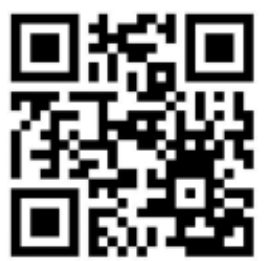

received

October 15, 2017 accepted

December 14, 2017

published online

February 28, 2018

www.thieme.com/skullbasevideos

www.thieme.com/jnlsbvideos

DOI https://doi.org/

10.1055/s-0038-1625940. ISSN 2193-6331. (c) 2018 Georg Thieme Verlag KG Stuttgart · New York
License terms

(ㄷ) (i) $\ominus$ (\$) 


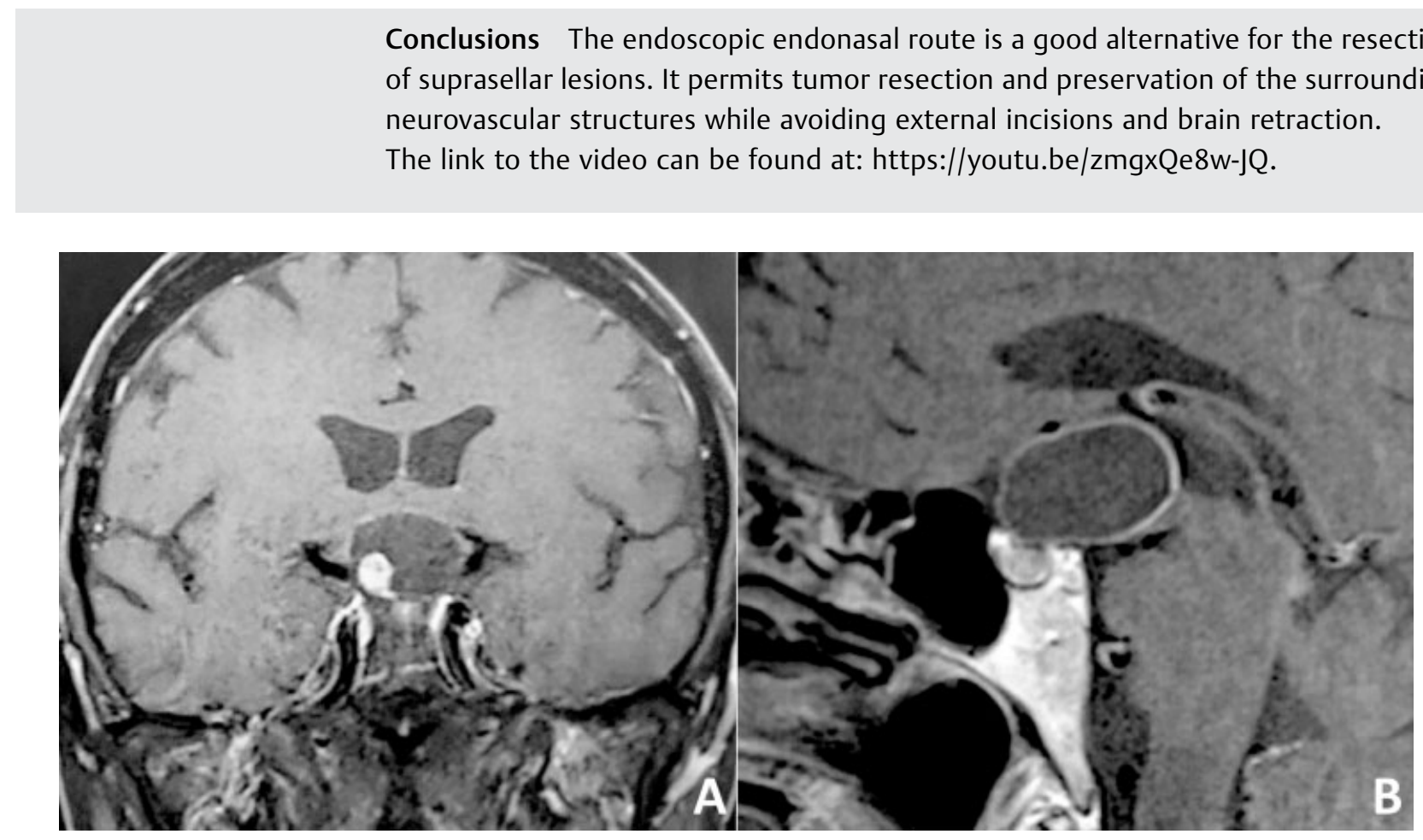

Fig. 1 Preoperative magnetic resonance images of a 72-year-old male patient with a large suprasellar craniopharyngioma. The lesion compressed was retrochiasmatic and compressed the optic chiasm from posterior to anterior. It also extended posteriorly into the interpeduncular cistern. (A) Coronal and (B) sagittal image.

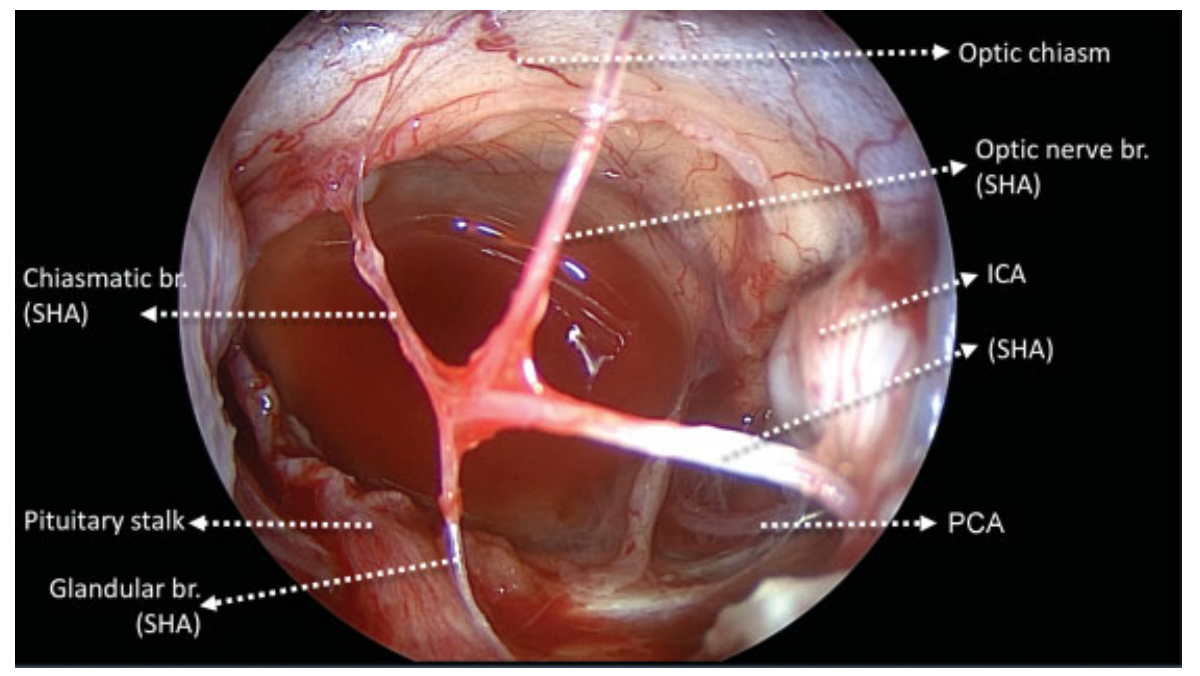

Fig. 2 An endoscopic endonasal transtuberculum transplanum approach was performed for the resection of the large suprasellar craniopharyngioma. Intraoperative picture demonstrating the relevant anatomy. Abbreviations: SHA, left superior hypophyseal artery; br., branch; ICA, left internal carotid artery; PCA, left posterior communicating artery.

\section{Conflict of Interest}

None.

\section{Acknowledgments}

The authors acknowledge all other physicians that helped to take care of the patient featured in this video, especially Dr. Leonardo Balsalobre, Dr. Matheus Fernandes de Oliveira, and Dr. José Francisco Pereira Júnior.

\section{References}

1 Stamm AC, Vellutini E, Harvey RJ, Nogeira JF Jr, Herman DR. Endoscopic transnasal craniotomy and the resection of craniopharyngioma. Laryngoscope 2008;118(07):1142-1148

2 Stamm AC, Vellutini E, Balsalobre L. Craniopharyngioma. Otolaryngol Clin North Am 2011;44(04):937-952, viii viii.

3 Beer-Furlan A, Jamshidi AO, Carrau RL, Prevedello DM. Letter to the Editor. Surgical strategy for craniopharyngiomas and the tumorinfundibulum relationship. Neurosurg Focus 2017;43(01):E8

4 Stamm AC, Pignatari S, Vellutini E, Harvey RJ, Nogueira JF Jr. A novel approach allowing binostril work to the sphenoid sinus. Otolaryngol Head Neck Surg 2008;138(04):531-532 